\title{
Revisiting the isolation source after half a century: Emericellopsis mirabilis on a yellow-green alga
}

\author{
Yusuke Takashima ${ }^{\mathrm{a},{ }^{*}}$, Takeshi Nakayama ${ }^{\mathrm{b}}$, Yousuke Degawa ${ }^{\mathrm{a}}$. \\ ${ }^{a}$ Sugadaira Research Station, Mountain Science Center, University of Tsukuba, Sugadairakogen 1278-294, Nagano 386-2204, Japan \\ ${ }^{b}$ Graduate School of Life and Environmental Sciences, University of Tsukuba, Tennodai 1-1-1, Tsukuba, Ibaraki 305-8572, Japan
}

\begin{abstract}
Fungi-algae interactions, such as lichen-forming fungi and parasitic chytrids on phytoplankton, are common in ecosystems. In contrast, interactions between filamentous fungi and soil algae that can be observed with the naked eye have been given little attention and remain unexplored. Here, we report a fungus that was associated with a visible symptom of dead algae on a soil surface in Sugadaira-kogen, Nagano, central Japan. Acremonium-like conidiophores were growing on vesicles and dead bodies of a yellow-green alga, Botrydium granulatum. The fungus was identified as Emericellopsis mirabilis based on its morphology by microscopic observation, phylogenetic analysis, and the similarity of the isolation substrate with the first description of the species. Co-culture experiments showed a filamentous cell differentiation of the alga by the fungus, but no harmful or beneficial effects on algal growth. Therefore, we speculate that $E$. mirabilis is a facultative parasite of $B$. granulatum under natural conditions.
\end{abstract}

Keywords: cleistothecia, fungi-algae interaction, homothallism, soil algae, Xanthophyceae.

Article history: Received 15 February 2021, Revised 30 March 2021, Accepted 30 March 2021, Available online 20 July 2021.

\section{Introduction}

Fungi-algae interactions are widespread in both aquatic and terrestrial ecosystems, with lichen-forming fungi and parasitic chytrids on phytoplankton playing important roles in the biogeochemical cycles in each of these ecosystems, respectively (Frenken et al., 2017; Green, Nash III, \& Lange, 2008; Nash III, 2008). However, it is still poorly understood how filamentous fungi and soil algae interact with each other. One such group of filamentous fungi is the genus Emericellopsis (Carreira et al., 2015; Carreira et al., 2020). Recently, some isolates phylogenetically related to this genus were obtained from macroalgae, including brown alga (Fucus) and green algae (Cladophora and Ulva) (Zuccaro, Summerbell, Gams, Schroers, \& Mitchell, 2004; Gonçalves, Vicente, Esteves, \& Alves, 2020). van Beyma thoe Kingma (1940) established the genus Emericellopsis (Hypocreales, Sordariomycetes) with descriptions of E. terricola var. terricola J.F.H. Beyma and E. terricola var. glabra J.F.H. Beyma. The genus has been considered somewhat ambiguous and was not reencountered in nature for a decade after the first description. However, a gradual accumulation of isolates of this genus by several researchers, as well as the discovery of antibiotic-producing isolates and advances in drug discovery research, has made this genus a familiar one in the field of pharmaceutical research (Backus \&

\footnotetext{
* Corresponding author: Sugadaira Research Station, Mountain Science Center, University of Tsukuba, Sugadairakogen 1278-294, Nagano 386-2204, Japan. E-mail address: yusuke.takashima.senmu@gmail.com (Y. Takashima).
}

Orpurt, 1961). Species of the genus Emericellopsis, including Acremonium tubakii W. Gams, which is phylogenetically related to this genus, are often found in aquatic or moist habitats (Tubaki, 1973; Zuccaro et al., 2004; Grum-Grzhimaylo, Georgieva, Debets, \& Bilanenko, 2013; Phookamsak et al., 2019; Gonçalves et al., 2020). The number of isolates and species of this genus has increased following the discovery and exploration of such habitats. The yellow-green alga, Botrydium granulatum (L.) Greville (Botrydiales, Xanthophyceae), is regarded as a representative member of soil or mud algae and is globally widespread. This species is widely distributed around wet and muddy places in Japan, such as paddy fields, other agricultural fields, irrigation or drainage ditches, ponds, and wetlands in suburban residential areas (Kamiya, 1960). In the present study, an isolate of the genus Emericellopsis that occurred on B. granulatum beside an agricultural field was obtained. The isolate was morphologically, phylogenetically, and ecologically identified as E. mirabilis (Malan) Stolk. As far as the authors are aware, this is the first formal report of the isolation of this species from yellow-green algae.

\section{Materials and methods}

\subsection{Algal sample}

The restrictions on travel brought about during the COVID-19 pandemic have encouraged researchers to focus on studying nearby places. White circles were formed on a soil surface on a farm 
road in front of the first author's house, located in Sugadaira-kogen, Nagano, central Japan. A small stream is present beside the farm road, which is flooded during heavy rainfall. After rain, the place becomes muddy but is soon dry again during sunny weather. Around the circles, brownish to whitish colonies of an alga were observed. Following to the monograph of three Botrydium spp. in central Japan reported by Kamiya (1960), the alga was distinguished from B. divisum M.O.P. Iyengar and B. tuberosum M.O.P. Iyengar based on unbranched solitary vesicles and no cysts on rhizoids, respectively, and identified as $B$. granulatum (data not shown). The algal colony was collected, moved to the laboratory, and examined under the stereomicroscopes SZ61 (Olympus Corp., Tokyo, Japan), SZX16 (Olympus) equipped with a camera DP21 (Olympus), and SZH10 (Olympus) equipped with a camera EOS kiss X8i (Canon, Tokyo, Japan). Aplanospores of B. granulatum were isolated onto Bold's basal medium (BBM) agar using a flame-sterilized fine needle and incubated under irradiation with approximately $20 \mu \mathrm{mol} \mathrm{m}{ }^{-2} \mathrm{~s}^{-1}$ and a $16 \mathrm{~h}$ light $\left(20^{\circ} \mathrm{C}\right) / 8 \mathrm{~h}$ dark $(20$ $\left.{ }^{\circ} \mathrm{C}\right)$ cycle. BBM agar was made according to the following recipe (Bischoff \& Bold, 1963): $10 \mathrm{~mL}$ of each stock solution of $25 \mathrm{~g} / \mathrm{L}$ $\mathrm{NaNO}_{3}$ (Junsei Chemical Co., Ltd., Tokyo, Japan), 2.5 g/L Ca$\mathrm{Cl}_{2} \cdot 2 \mathrm{H}_{2} \mathrm{O}$ (Iwai Chemicals Company Ltd., Tokyo, Japan), $7.5 \mathrm{~g} / \mathrm{L}$ $\mathrm{MgSO}_{4} \cdot 7 \mathrm{H}_{2} \mathrm{O}$ (Junsei), $7.5 \mathrm{~g} / \mathrm{L} \mathrm{K}_{2} \mathrm{HPO}_{4} \cdot 3 \mathrm{H}_{2} \mathrm{O}$ (Kanto Chemical Co., Inc., Tokyo, Japan), $17.5 \mathrm{~g} / \mathrm{L} \mathrm{KH}_{2} \mathrm{PO}_{4}$ (Wako Pure Chemical Industries, Osaka, Japan) and $2.5 \mathrm{~g} / \mathrm{L} \mathrm{NaCl}$ (Junsei); as well as $6 \mathrm{~mL}$ of PIV metal solution containing $750 \mathrm{mg} / \mathrm{L} \mathrm{Na}{ }_{2}$ EDTA $2 \mathrm{H}_{2} \mathrm{O}$ (Dojindo Laboratories, Kumamoto, Japan), $97 \mathrm{mg} / \mathrm{L} \mathrm{FeCl}_{3} \cdot 6 \mathrm{H}_{2} \mathrm{O}$ (Wako), 41 $\mathrm{mg} / \mathrm{L} \mathrm{MnCl} \cdot 4 \mathrm{H}_{2} \mathrm{O}$ (Wako), $5 \mathrm{mg} / \mathrm{L} \mathrm{ZnCl}_{2}$ (Kanto Chemical), 4 $\mathrm{mg} / \mathrm{L} \mathrm{Na}_{2} \mathrm{MoO}_{4} \cdot 2 \mathrm{H}_{2} \mathrm{O}$ (Wako), and $2 \mathrm{mg} / \mathrm{L} \mathrm{CoCl}_{2} \cdot 6 \mathrm{H}_{2} \mathrm{O}$ (Wako); and finally $15 \mathrm{~g}$ agar (Wako) in $1 \mathrm{~L}$ distilled water.

\subsection{Isolation of Acremonium-like asexual stage}

Conidia of an Acremonium-like asexual stage found on the vesicles of $B$. granulatum were isolated on ${ }_{\mathrm{LC}} \mathrm{A}$ (Miura agar) medium [0.2 g yeast extract (Difco, Sparks, MD, USA), 1 g glucose (Wako), 2 $\mathrm{g} \mathrm{NaNO}_{3}$ (Wako), $1 \mathrm{~g} \mathrm{KH}_{2} \mathrm{PO}_{4}$ (Wako), $0.2 \mathrm{~g} \mathrm{KCl}$ (Kanto Chemical), $0.2 \mathrm{~g} \mathrm{MgSO}_{4} \cdot 7 \mathrm{H}_{2} \mathrm{O}$ (Junsei), and $15 \mathrm{~g}$ agar (Wako) in $1 \mathrm{~L}$ distilled water] (Miura \& Kudo, 1970) using a flame-sterilized fine needle and incubated at room temperature (ca. $20-25^{\circ} \mathrm{C}$ ). After the establishment of the isolate, single-spore isolation was conducted. The algal colonies that occurred together with the Acremonium-like asexual stage were inactivated by drying in an oven at $60^{\circ} \mathrm{C}$ for $6 \mathrm{~d}$ and deposited as a specimen in the Kanagawa Prefectural Museum of Natural History (KPM, Kanagawa Pref., Japan; KPMNC0028609). A living culture of the isolate in pure culture and its dried plate specimen were deposited in the NITE Biological Resource Center (NBRC, Chiba Pref., Japan; NBRC 114971) and the KPM (KPM-NC0028608), respectively.

\subsection{Morphological observation}

The isolate that was incubated for $2-3$ wk on ${ }_{\mathrm{LC}} \mathrm{A}$ medium was used for the morphological observation of both the asexual and sexual stages. Both stages were mounted with water and observed under light microscopes BX50 (Olympus) equipped with a camera EOS kiss X8i (Canon) and BX53 (Olympus) equipped with a camera DP73 (Olympus).

\subsection{DNA extraction, $P C R$, and DNA sequencing}

Template DNA was extracted from fungal mycelia using Prep$\operatorname{man}^{\mathrm{TM}}$ Ultra sample reagent (Applied Biosystems, Foster City, CA,
USA) following the manufacturer's instructions. For the PCR amplification of the ITS1-5.8S-ITS2 region, PCR was conducted following Takashima et al. (2018) using the ITS5-LR5 primer set (Vilgalys \& Hester, 1990; White, Bruns, Lee, \& Taylor, 1990) and Ex Taq HS polymerase (Takara Bio, Otsu, Japan). For the PCR amplification of the partial $\beta$-tubulin (tub2) gene, the T10 (O'Donnell \& Cigelnik, 1997) and Bt2b (Glass \& Donaldson, 1995) primer set was used. A PCR mixture containing $1.0 \mu \mathrm{L}$ of template DNA, $1.5 \mu \mathrm{L}$ of each primer solution, $10 \mu \mathrm{L}$ of $2 \mathrm{mM}$ dNTPs, $1.0 \mu \mathrm{L}$ of $1.0 \mathrm{U} / \mu \mathrm{L}$ KOD FX Neo DNA polymerase (Toyobo, Osaka, Japan), $25 \mu \mathrm{L}$ of $2 \times$ PCR Buffer for KOD FX Neo DNA polymerase, and $10 \mu \mathrm{L}$ of sterilized deionized water was prepared. PCR amplification of the tub2 gene was performed as follows: an initial denaturation step of 2 min at $94{ }^{\circ} \mathrm{C}$, followed by 35 cycles of $98^{\circ} \mathrm{C}$ for $10 \mathrm{~s}, 65^{\circ} \mathrm{C}$ for $30 \mathrm{~s}$, and $68{ }^{\circ} \mathrm{C}$ for $30 \mathrm{~s}$. PCR products were purified using polyethylene glycol and ethanol precipitation, and a cycle sequence reaction was then performed with a BigDye Terminator Cycle Sequencing Ready Reaction Kit (Applied Biosystems) following the manufacturer's instructions. For the cycle sequencing of the ITS region and the tub2 gene, the ITS5 and ITS4 (White et al., 1990), and the T10 and $\mathrm{Bt} 2 \mathrm{~b}$ primers were used, respectively. Cycle sequencing products were purified by ethanol precipitation, and electrophoresis was performed using the Applied Biosystems 3130xl genetic analyzer (Applied Biosystems) to determine nucleotide sequences. The sequences obtained from the forward and reverse primers of each gene region were assembled into a single sequence using GeneStudio Professional software version 2.2.0.0 (http://www.genestudio. $\mathrm{com} /$ ). Sequence data of the isolate was deposited in GenBank [MW595829 (ITS), LC605902 (tub2)].

\subsection{Phylogenetic analysis}

ITS and tub2 sequences of Emericellopsis spp. and related species were obtained from GenBank (Supplementary Table S1). ITS and $t u b 2$ sequences were aligned independently using MAFFT v7.453 (Katoh \& Standley, 2013) and poorly aligned regions were trimmed from each multiple sequence alignment with trimal v1.4 (Capella-Gutiérrez, Silla-Martínez, \& Gabaldón, 2009). Sequence alignments were viewed using MEGA X software (Kumar, Stecher, Li, Knyaz, \& Tamura, 2018) and poorly aligned positions at either end of the alignments were removed manually. The alignments for each gene region were then concatenated (404 positions for ITS and 193 positions for tub2, resulting in 597 positions in the final data set) and compared using the partition model in Kakusan4 (released on 4.0.2016.11.07; Tanabe, 2011). Prior to maximum likelihood (ML) phylogenetic analysis, nucleotide substitution model selection was performed using ModelTest-NG v0.1.6 (Darriba et al., 2020). The ML phylogenetic analysis was performed using RAxML-NG v1.0.0 (Kozlov, Darriba, Flouri, Morel, \& Stamatakis, 2019) with a 1,000 bootstrap analysis. The partition model was set as "--brlen linked" because the "equalrate" model was selected (lowest AIC) by Kakusan4. Following the model selection by ModelTest-NG, the nucleotide substitution model of the ITS and tub2 regions were TIM1+G4 and TrNef $+\mathrm{G} 4$, respectively. Sarocladium spp. were selected as the outgroup. The alignments and trees were deposited in TreeBASE (https://treebase.org/treebase-web/home. html) under the study ID S27767.

\subsection{Co-culture experiment}

In preparation for the co-culture experiment, cultures of the fungus were incubated for $14 \mathrm{~d}$ on ${ }_{\mathrm{LC}} \mathrm{A}$ medium at $23{ }^{\circ} \mathrm{C}$ and cultures of B. granulatum were incubated for 14-21 d in $25 \mathrm{~mL}$ liquid 
BBM using the same conditions described in the algal isolation step above. The co-culture experiment was also conducted on the BBM agar medium and incubated using the same conditions as above. In the center of the medium, $200 \mu \mathrm{L}$ of the pre-incubated Botrydium culture was spread in a line. Then, 3 blocks (ca. $5 \mathrm{~mm}^{3}$ ) of ${ }_{\mathrm{LC}} \mathrm{A}$ agar containing the fungus or the medium only were placed onto the BBM agar medium, $1.5 \mathrm{~cm}$ away from the Botrydium-inoculated line (Supplementary Fig. S1). A BBM agar inoculated with Botrydium only was also prepared as a negative control. These three inoculation conditions (fungus on ${ }_{\mathrm{LC}} \mathrm{A}$ agar + Botrydium, ${ }_{\mathrm{LC}} \mathrm{A}$ agar + Botrydium, Botrydium) were prepared in duplicate. After $7 \mathrm{~d}$ incubation, the algal growth for each condition was observed.

\section{Results and Discussion}

\subsection{Identification of the fungus occurring on B. granulatum as E. mirabilis}

Brownish or whitish colonies of $B$. granulatum were observed on dried mud (Fig. 1A-E). The brownish part was colored due to the occurrence of an Acremonium-like asexual stage on the vesicles and decayed bodies of B. granulatum (Fig. 1G-J). The vesicles were surrounded by hyphae of the fungus, but the hyphae did not enter the cells of $B$. granulatum (Fig. $1 \mathrm{~K}$ ). Under culture, the fungus formed identical conidiophores to those observed in nature (Fig. $2 \mathrm{H}, \mathrm{I})$. In addition, sexual stage cleistothecia were homothallically formed within the agar (Fig. 2B). Ascospores were ellipsoidal, dark brown, and had lacinate brownish wings (Fig. 2D-G). The asexual stage was Acremonium-like and conidia were generally smaller than ascospores (Fig. 2H-K). Referring to the comprehensive study of the Emericellopsis genus by Gams (1971), the morphology of the
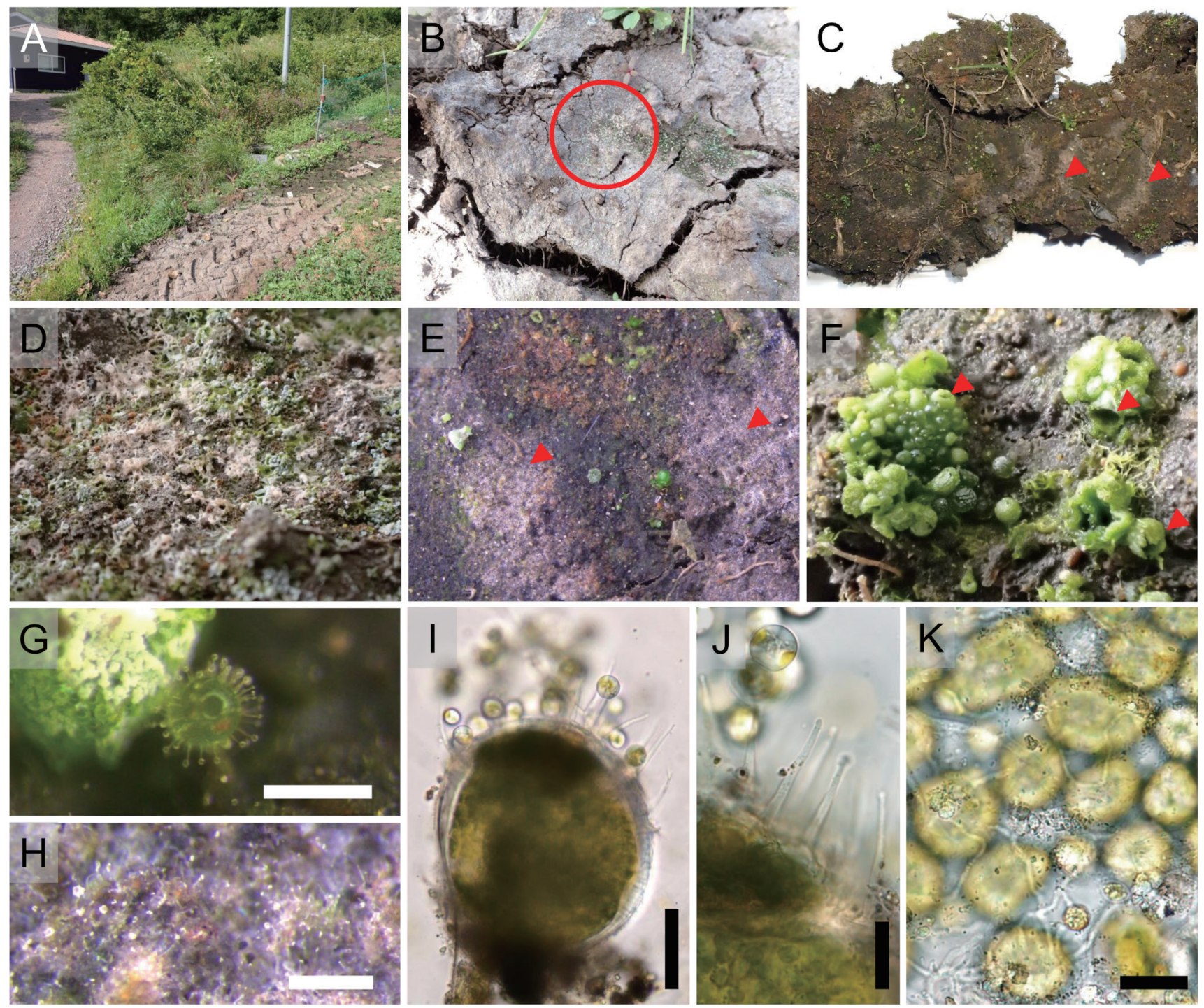

Fig. 1. The occurrence of Emericellopsis mirabilis on Botrydium granulatum. A: A farm road in front of the first author's house. B: A brownish colony of B. granulatum (circle). C: Whitish circles (arrowheads) on the soil surface around the B. granulatum colonies (KPM-NC0028609). D: Magnified image of the circle in B. E: Magnified image of the arrowheads in C. F: Spheroidal masses of mature vesicles of healthy B. granulatum and cup-shaped vesicles following the production of aplanospores (arrowheads). G, I, J; Acremonium-like asexual stage of E. mirabilis occurring on the vesicle of B. granulatum. H: Acremonium-like asexual stage of E. mirabilis occurring on the dead bodies of B. granulatum. K: Hyphal covering by E. mirabilis on the vesicle. The hyphae did not enter the inside of the vesicle. Bars: G, H $200 \mu \mathrm{m}$; 50 $\mu \mathrm{m} ; \mathrm{J}, \mathrm{K} 20 \mu \mathrm{m}$. 

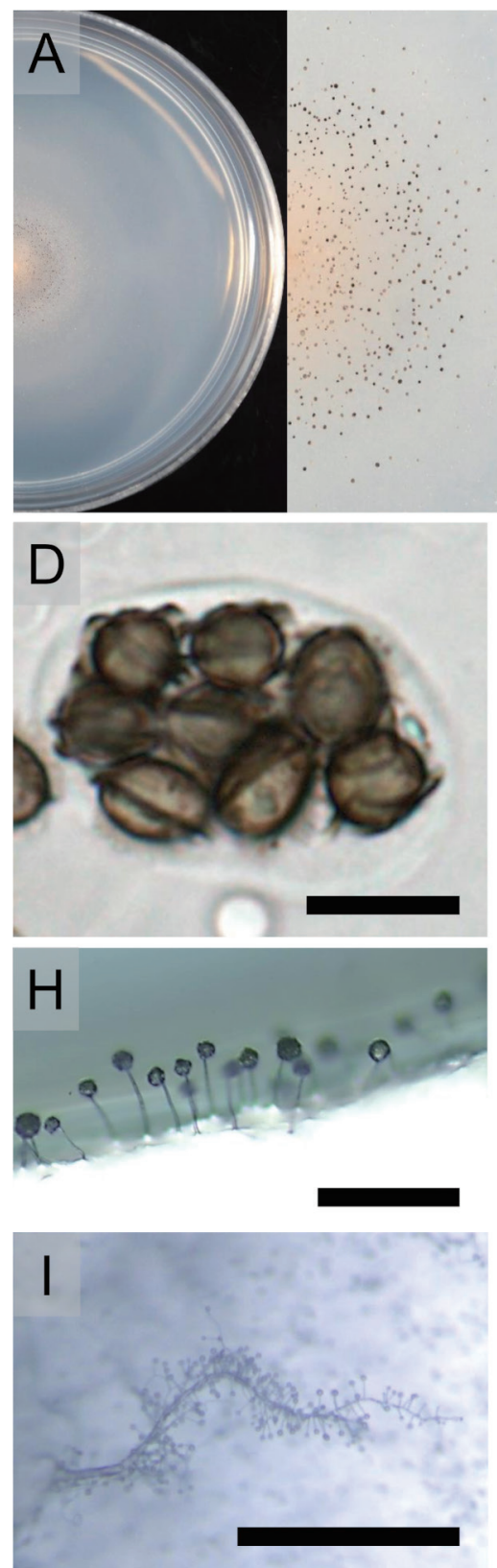

Fig. 2. Microscopic characters of Emericellopsis mir A dotted ascospore surface between the wings (arrowhead). $\mathrm{H}$ : Conidiophores on the agar surface. I: Conidiophores on aerial hyphae. J: Acremonium-like conidiophores. K: Conidia. Bars: B, I $500 \mu \mathrm{m}$; C, H $100 \mu \mathrm{m}, \mathrm{D}, \mathrm{E}, \mathrm{K} 10 \mu \mathrm{m}$; F, G $5 \mu \mathrm{m}$; J $20 \mu \mathrm{m}$.

isolate was deemed to be similar to E. glabra (J.F.H. Beyma) Backus \& Orpurt, E. mirabilis, and E. robusta Emden \& W. Gams as it had ascospores larger than $5 \mu \mathrm{m}$ and brown prominent wings. However, following more detailed comparisons, E. glabra and E. robusta were distinguished from the isolate as they possess non-lacinate wings and conidia larger than ascospores, respectively. Therefore, E. mirabillis most closely resembles the present isolate as they both possess ascospores with lacinate wings and conidia smaller than ascospores.

From the ML phylogeny, Emericellopsis spp. and some Acremonium spp. were clustered into either a "Marine/Soda soil clade" or "Terrestrial clades" (log-likelihood: -2727.155868, Fig. 3) designated by Gonçalves et al. (2020). The ML tree showed that the present isolate was included in the "Terrestrial clades" and formed a clade with the sequences from the isolates of E. mirabilis including extype with $71 \%$ bootstrap support. The ML tree showed that the present isolate was closely related to sequences from other strains of E. mirabilis. Therefore, based on the morphological and molecular information obtained here, the present isolate was identified as E. mirabilis, and a detailed description is given as follows.

Emericellopsis mirabilis (Malan) Stolk, Transactions of the British Mycological Society 38: 421, 1955.

Figs. 1, 2 三 Peyronellula mirabilis Malan, Mycopathologia et Mycologia Applicata 6: 173, 1952.

Colonies slow-growing, ca. $4 \mathrm{~cm}$ diam in $21 \mathrm{~d}$ on ${ }_{\mathrm{LC}} \mathrm{A}$ at $23^{\circ} \mathrm{C}$, salmon-pink, conidiophores mostly occurred around the inoculum 


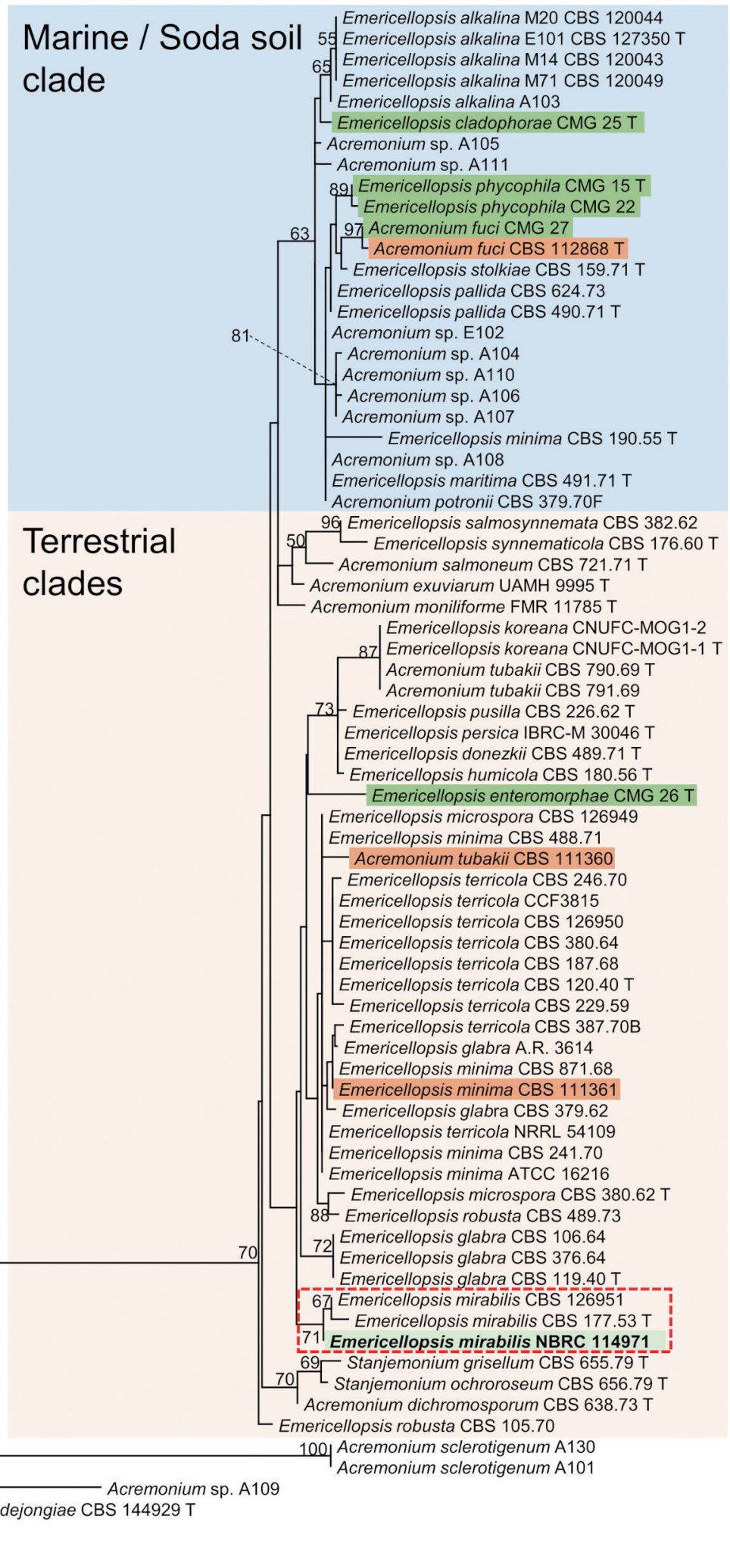

0.05

Fig. 3. Maximum likelihood (ML) phylogenetic tree of Emericellopsis spp. based on the concatenated sequences of the ITS region (404 positions) and the partial tub2 gene (193 positions) using RAxML-NG v1.0.0 software with the TIM1+G4 (ITS) and TrNef+G4 (tub2) substitution models and bootstrapping (1,000 replicates). Bootstrap values $\geq 50 \%$ are shown at nodes. The value of the log likelihood was -2727.155868 . Sarocladium spp. were used as the outgroup. Emericellopsis spp. and related species were clustered into a "Marine/Soda soil clade" or "Terrestrial clades". Taxa names of the isolates obtained from algae are shown with different colored backgrounds corresponding to green algae (green), brown algae (brown), and yellow-green alga (yellow green). The clade containing E. mirabilis is indicated by a red box with dashed lines. "T" beside each strain name indicates the strains as ex-type strain. 
point, cleistothecia abundantly appeared as black dots in the agar within 1 mo. Hyphae hyaline, anastomosis present. Cleistothecia produced within the agar, homothallic, mostly 8-spored, spherical, hyaline, $34-107 \mu \mathrm{m}$ diam, $78 \mu \mathrm{m}$ diam on average $( \pm 3.9 \mu \mathrm{m}$ of standard error). Asci globose to subglobose, hyaline, 18-28 × 16-27 $\mu \mathrm{m}$, 1.0-1.6 in length/width ratio (L/W). Ascospores ellipsoidal, dark brown, 8.4-12.8 $\times 5.2-8.2 \mu \mathrm{m}, \mathrm{L} / \mathrm{W} 1.3-1.8$, commonly with an oil drop, wings $6,1.0-2.8 \mu \mathrm{m}$ wide, brown, lacinate, ascospore surface between the wings dotted. Conidiophores hyaline, erect, arising from agar surface or sometimes formed on aerial hyphae, 35-55 $\mu \mathrm{m}$ long, septate at the base, tapering from 2.2-3.0 $\mu \mathrm{m}$ near the base to 1.0-1.7 $\mu \mathrm{m}$. Conidia ellipsoidal to cylindrical, hyaline, 4.2-9.5 $\times$ 1.9-3.3 $\mu \mathrm{m}, \mathrm{L} / \mathrm{W} 1.9-3.6$.

The size range of ascospores in the original description by Malan (1952) and Gams (1971) overlapped with that of the present isolate $(8.4-12.8 \times 5.2-8.2 \mu \mathrm{m}, 9.8 \times 6.4 \mu \mathrm{m}$ on average $)$. The morphology of the conidia of E. mirabilis was originally described as Acremonium-like, hyaline, oblong-ellipsoidal or sub-cylindrical, $6-11 \times 2.5-3 \mu \mathrm{m}$ in size, mostly $8 \times 3 \mu \mathrm{m}$ (Malan, 1952). This size range also overlapped with that of the present isolate $(4.2-9.5 \times$ $1.9-3.3 \mu \mathrm{m}, 6.4 \times 2.4 \mu \mathrm{m}$ on average).

The type strain of E. mirabilis (CBS 177.53) was isolated from "dead protonema of moss" in damp soil (Malan, 1952). Malan (1952) observed the habitat as brown or white plaques that covered the ground and described the isolation source as the organism forming rhizoids and spheroidal masses, some of which were producing tiny cups. This habitat observation is quite similar to that of this study. In the field, B. granulatum was forming vesicles as spheroidal masses on the ground and the mature vesicles superficially appeared to be cup-shaped following the production of aplanospores (Fig. 1F). Therefore, the description of the habitat of E. mirabilis by Malan (1952) seems to suggest Botrydium algae as a possible isolation source, similar to this study. In addition to the above-mentioned morphological and phylogenetic similarities, comparison of the ecological properties of the present isolate with type materials, strongly supports the identification of the isolate obtained from B. granulatum in this study as E. mirabilis. Previously, only four Emericellopsis spp. (E. humicola (Cain) Cain ex Grosklags \& Swift, E. microspora Backus \& Orpurt, E. minima Stolk, and E. sphaerospora Udagawa \& Furuya) have been reported from Japan (Tubaki, 1973; Udagawa \& Furuya, 1988). Therefore, this discovery of E. mirabilis is new to Japan.

\subsection{Relationship between terrestrial algae and Emericellopsis spp.}

The observed brownish or whitish substrates of E. mirabilis on the soil surface in this study indicate that the fungus had a negative effect on B. granulatum (Fig. 1B-E). However, the in vitro co-culture of the isolates of E. mirabilis and B. granulatum incubated on BBM agar showed no apparant growth reduction of the alga (Fig. 4). This observation is similar to the findings of Malan (1952) that E. mirabilis has not showed any parasitic behavior on "protonema of moss" (possibly Botrydium algae as discussed in above) in his inoculation experiment. The co-culture experiment also showed a filamentous cell differentiation of B. granulatum beside the fungal inoculation points (Fig. 4). Under other conditions, the filamentous cells were not formed and all algal cells remained spherical. These findings were observed across all 6 inoculation points in each condition. This cell differentiation could be due to changes in cell division caused by secondary metabolites, such as antimitotic toxins, secreted by the fungus. An antitumor agent, emericellipsin
A, was reported from another species of Emericellopsis (Rogozhin et al., 2018). The filamentous cells also resembled the germinated aplanospores. These observations may indicate that $E$. mirabilis is a facultative parasite of $B$. granulatum under natural conditions, and that this fungus can disturb the growth, or promote the germination, of B. granulatum. In the intertidal Wadden Sea, ring-like structures were found on photosynthetic microbial mats mixed population of cyanobacteria and diatoms, and the structures were demonstrated by the inoculation of the cyanobacteria-degrading agent Emericellopsis sp. (Carreira et al., 2015). Parasitic or degrading-agent behaviors of Emericellopsis toward algae are still ambiguous; however, some recently described species of Emericellopsis, such as E. cladophorae M. Gonçalves, T. Vicente \& A. Alves, E. enteromorphae M. Gonçalves, T. Vicente \& A. Alves, and E. phycophila M. Gonçalves, T. Vicente \& A. Alves, have also highlighted the interesting relationships between algae and this genus (Gonçalves et al., 2020). Emericellopsis spp. are often isolated from freshwater environments and E. minima was reported as an algal-lysing agent against green algae such as Chlorella simplex (Artari) Migula and Chlorococcum hypnosporum Starr (Redhead \& Wright, 1978). In contrast, other species, especially those grouped into the "Terrestrial clade", are often isolated from ambiguous wet substrates such as wet soil and water (Supplementary Table S1). The relationship between Botrydium algae and E. mirabilis, observed in this study as well as a previous study (Malan, 1952), may explain why Emericellopsis spp. prefer such wet substrates, as they have an affinity for terrestrial algal habitats.

During the algal isolation step and the co-culture experiment of this study, bacterial growth was observed around the algal cells on BBM medium. One of the bacteria was isolated from the medium and identified as a member of Rhizobium following analysis of the 16S rRNA gene (data not shown). This genus is known as a growth-promoting bacteria of several green algae (Kim, Ramanan, Cho, Oh, \& Kim, 2014). The study of algae-bacteria interactions are also important for understanding ecosystems (Ramanan, Kim, Cho, Oh, \& Kim, 2016). As noted in the introduction, some isolates of Emericellopsis spp. are known to produce antibiotics (Backus \& Orpurt, 1961). The presence of Emericellopsis spp. around algae seems to influence the growth of algae by reduction of the growth of the growth-promoting bacteria of algae by secretion of antibiotics. Thus, further studies are needed to reveal how much impact Emericellopsis spp. have upon algae-bacteria interactions and their contribution to ecosystem services.

\section{Acknowledgment}

We thank Dr. Hiroshi Masumoto for sharing the knowledge about algal culture techniques and staffs of CBS-KNAW culture collection for providing information about some Emericellopsis isolates. This research was supported by the JSPS KAKENHI Grant Number 19H03281 to YD as the principal investigator, and TN and YT as co-investigators.

\section{Disclosure}

The authors declare no conflicts of interest. All the experiments undertaken in this study comply with the current laws of the country where they were performed.

\section{References}

Backus, M. P., \& Orpurt, P. A. (1961). A new Emericellopsis from Wisconsin, with notes on other species. Mycologia, 53, 64-83. 

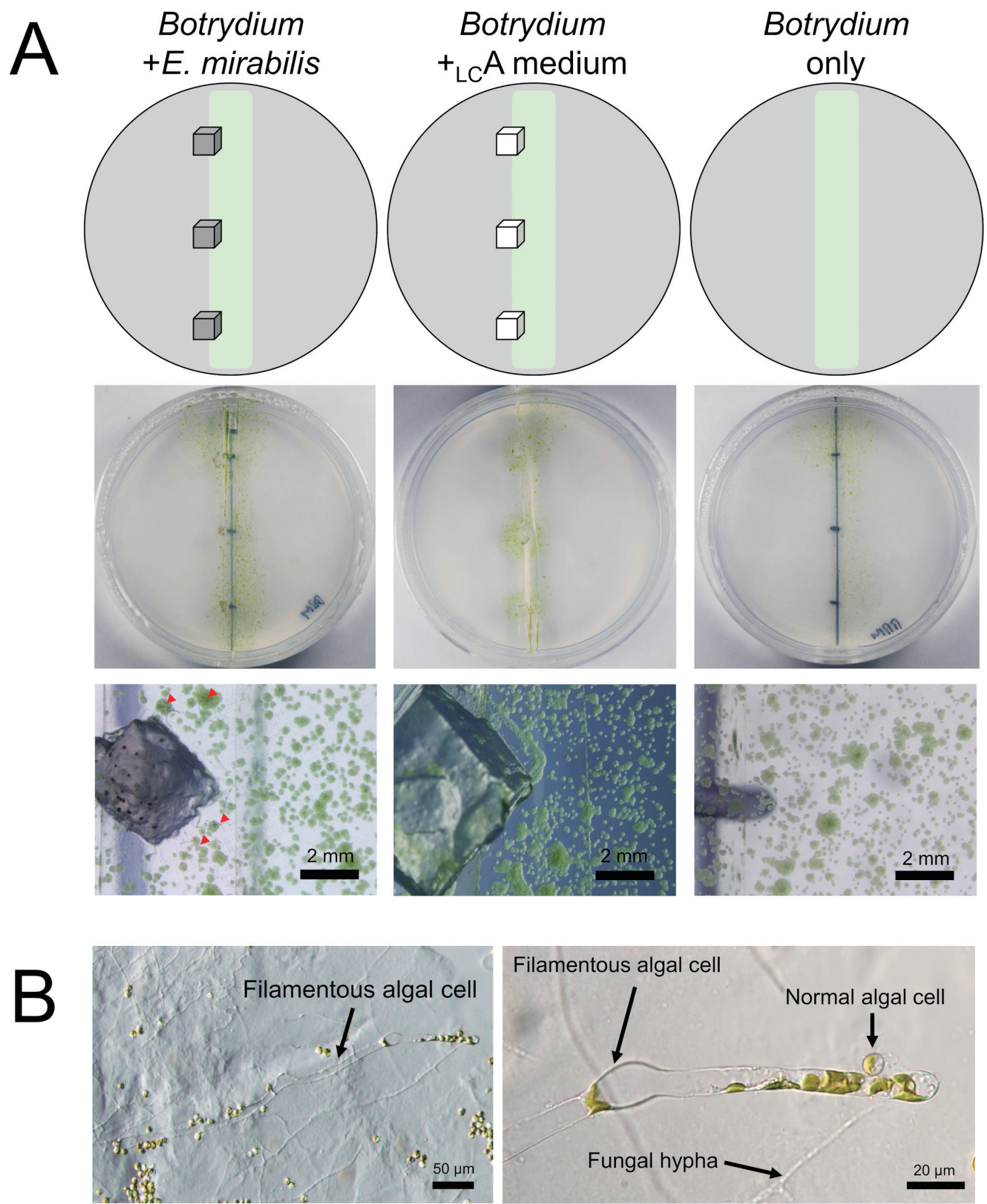

Fig. 4. Co-culture experiment of Emericellopsis mirabilis NBRC 114971 and Botrydium granulatum. A: Algal growth under three different conditions. Reduction of algal growth by E. mirabilis was not observed; however, filamentous cells were found in the co-culture condition (arrowhead). B: Microscopic images of the filamentous cells observed in the co-culture condition. 
Bischoff, H. W., \& Bold, H. C. (1963). Phycological studies IV. Some soil algae from enchanted rock and related algal species. Austin, TX: University of Texas.

Capella-Gutiérrez, S., Silla-Martínez, J. M., \& Gabaldón, T. (2009). trimAl: a tool for automated alignment trimming in large-scale phylogenetic analyses. Bioinformatics, 25, 1972-1973. https://doi.org/10.1093/bioinformatics/btp348

Carreira, C., Lønborg, C., Kühl, M., Lillebø, A. I., Sandaa, R. A., Villanueva, L., \& Cruz, S. (2020). Fungi and viruses as important players in microbial mats. FEMS Microbiology Ecology, 96, fiaa187. https://doi.org/10.1093/femsec/ fiaa 187

Carreira, C., Staal, M., Falkoski, D., De Vries, R. P., Middelboe, M., \& Brussaard, C. P. (2015). Disruption of photoautotrophic intertidal mats by filamentous fungi. Environmental Microbiology, 17, 2910-2921. https://doi.org/10.1111/14622920.12835

Darriba, D., Posada, D., Kozlov, A. M., Stamatakis, A., Morel, B., \& Flouri, T. (2020) ModelTest-NG: a new and scalable tool for the selection of DNA and protein evolutionary models. Molecular Biology and Evolution, 37, 291-294. https://doi. org/10.1093/molbev/msz189

Frenken, T., Alacid, E., Berger, S. A., Bourne, E. C., Gerphagnon, M., Grossart, H. P., Gsell, A. S., Ibelings, B. W., Kagami, M., Küpper, F. C., Letcher, P. M., Loyau, A., Miki, T., Nejstgaard, J. C., Rasconi, S., Reñé, A., Rohrlack, T., Rojas-Jimenez, K. Schmeller, D. S., Scholz, B., Seto, K., Sime-Ngando, T., Sukenik, A., Van de Waal, D. B., Van den Wyngaert, S., Van Donk, E., Wolinska, J., Wurzbacher, C., \& Agha, R. (2017). Integrating chytrid fungal parasites into plankton ecology: research gaps and needs. Environmental Microbiology, 19, 3802-3822. https:// doi.org/10.1111/1462-2920.13827

Gams, W. (1971). Cephalosporium-artige Schimmelpilze (Hyphomycetes) (in German). Stuttgart: Gustav Fischer Verlag.

Glass, N. L., \& Donaldson, G. (1995). Development of primer sets designed for use with PCR to amplify conserved genes from filamentous ascomycetes. Applied and Environmental Microbiology, 61, 1323-1330.

Gonçalves, M. F. M., Vicente, T. F. L., Esteves, A. C., \& Alves, A. (2020). Novel halotolerant species of Emericellopsis and Parasarocladium associated with macroalgae in an estuarine environment. Mycologia, 112, 154-171. https://doi.org/ 10.1080/00275514.2019.1677448

Green, T. G. A., Nash III, T. H., \& Lange, O. L. (2008). Physiological ecology of carbon dioxide exchange. In: T. H. Nash III (Ed.), Lichen biology (2nd ed., pp. 152-181). Cambridge: Cambridge University Press.

Grum-Grzhimaylo, A. A., Georgieva, M. L., Debets, A. J., \& Bilanenko, E. N. (2013). Are alkalitolerant fungi of the Emericellopsis lineage (Bionectriaceae) of marine origin?. IMA fungus, 4, 213-228. https://doi.org/10.5598/imafungus.2013.04.02.07

Kamiya, T. (1960). On the Botrydium in the middle part of Japan (in Japanese). Journal of Japanese Botany, 35, 172-179.

Katoh, K., \& Standley, D. M. (2013). MAFFT multiple sequence alignment software version 7: improvements in performance and usability. Molecular Biology and Evolution, 30, 772-780. https://doi.org/10.1093/molbev/mst010

Kim, B. H., Ramanan, R., Cho, D. H., Oh, H. M., \& Kim, H. S. (2014). Role of Rhizobium, a plant growth promoting bacterium, in enhancing algal biomass through mutualistic interaction. Biomass and Bioenergy, 69, 95-105. https:// doi.org/10.1016/j.biombioe.2014.07.015

Kozlov, A. M., Darriba, D., Flouri, T., Morel, B., \& Stamatakis, A. (2019). RAxML-NG: a fast, scalable and user-friendly tool for maximum likelihood phylogenetic inference. Bioinformatics, 35, 4453-4455. https://doi.org/10.1093/bioinformatics/btz305

Kumar, S., Stecher, G., Li, M., Knyaz, C., \& Tamura, K. (2018). MEGA X: Molecular Evolutionary Genetics Analysis across computing platforms. Molecular Biology and Evolution, 35, 1547-1549. https://doi.org/10.1093/molbev/msy096

Malan, C. E. (1952). Sopra un interessante plectomicete umicolo nuovo per la scienza: Peyronellula mirabilis n.g. et n.sp. Mycopathologia et Mycologia Applicata, 6, 164-175. https://doi.org/10.1007/BF02081433

Miura, K., \& Kudo, M. (1970). An agar-medium for aquatic hyphomycetes (in Japanese). Transactions of the Mycological Society of Japan, 11, 116-118

Nash III, T. H. (2008). Nitrogen, its metabolism and potential contribution to ecosystems. In: T. H. Nash III (Ed.), Lichen biology (2nd ed., pp. 216-233). Cambridge: Cambridge University Press.

O’Donnell, K., \& Cigelnik, E. (1997). Two divergent intragenomic rDNA ITS2 types within a monophyletic lineage of the fungus Fusarium are nonorthologous. Molecular Phylogenetics and Evolution, 7, 103-116. https://doi.org/10.1006/ mpev.1996.0376

Phookamsak, R., Hyde, K. D., Jeewon, R., Bhat, D. J., Jones, E. B. G., Maharachchikumbura, S. S. N., Raspé, O., Karunarathna, S. C., Wanasinghe, D. N., Hongsanan, S., Doilom, M., Tennakoon, D. S., Machado, A. R., Firmino, A. L., Ghosh, A., Karunarathna, A., Mešić, A., Dutta, A. K., Thongbai, B., Devadatha, B., Norphanphoun, C., Senwanna, C., Wei, D., Pem, D., Ackah, F. K., Wang, G. N.,
Jiang, H. B., Madrid, H., Lee, H. B., Goonasekara, I. D., Manawasinghe, I. S., Kušan, I., Cano, J., Gené, J., Li, J., Das, K., Acharya, K., Raj, K. N. A., Latha, K. P. D., Chethana, K. W. T., He, M. Q., Dueñas, M., Jadan, M., Martín, M. P., Samarakoon, M. C., Dayarathne, M. C., Raza, M., Park, M. S., Telleria, M. T. Chaiwan, N., Matočec, N., de Silva, N. I., Pereira, O. L., Singh, P. N., Manimohan, P., Uniyal, P., Shang, Q. J., Bhatt, R. P., Perera, R. H., Alvarenga, R. L. M., Nogal-Prata, S., Singh, S. K., Vadthanarat, S., Oh, S. Y., Huang, S. K., Rana, S., Konta, S., Paloi, S., Jayasiri, S. C., Jeon, S. J., Mehmood, T., Gibertoni, T. B., Nguyen, T. T. T., Singh, U., Thiyagaraja, V., Sarma, V. V., Dong, W., Yu, X. D., Lu, Y. Z., Lim, Y. W., Chen, Y., Tkalčec, Z., Zhang, Z. F., Luo, Z. L., Daranagama, D. A., Thambugala, K. M., Tibpromma, S., Camporesi, E., Bulgakov, T., Dissanayake, A. J., Senanayake, I. C., Dai, D. Q., Tang, L. Z., Khan, S., Zhang, H., Promputtha, I., Cai, L., Chomnunti, P., Zhao, R. L., Lumyong, S., Boonmee, S., Wen, T. C., Mortimer, P. E., \& Xu, J. (2019). Fungal diversity notes 929-1036: taxonomic and phylogenetic contributions on genera and species of fungal taxa. Fungal Diversity, 95, 1-273. https://doi.org/10.1007/s13225-019-00421-w

Ramanan, R., Kim, B. H., Cho, D. H., Oh, H. M., \& Kim, H. S. (2016). Algae-bacteria interactions: evolution, ecology and emerging applications. Biotechnology Advances, 34, 14-29. https://doi.org/10.1016/j.biotechadv.2015.12.003

Redhead, K., \& Wright, S. J. (1978). Isolation and properties of fungi that lyse bluegreen algae. Applied and Environmental Microbiology, 35, 962-969.

Rogozhin, E. A., Sadykova, V. S., Baranova, A. A., Vasilchenko, A. S., Lushpa, V. A., Mineev, K. S., Georgieva, M. L., Kul'ko, A. B., Krasheninnikov, M. E., Lyundup, A. V., Vasilchenko, A. V., \& Andreev, Y. A. (2018). A novel lipopeptaibol emericellipsin A with antimicrobial and antitumor activity produced by the extremophilic fungus Emericellopsis alkalina. Molecules, 23, 2785. https://doi. org/10.3390/molecules23112785

Takashima, Y., Seto, K., Degawa, Y., Guo, Y., Nishizawa, T., Ohta, H., \& Narisawa, K. (2018). Prevalence and intra-family phylogenetic divergence of Burkholderiaceae-related endobacteria associated with species of Mortierella. Microbes and Environments, 33, 417-427. https://doi.org/10.1264/jsme2.ME18081

Tanabe, A. S. (2011). Kakusan4 and Aminosan: two programs for comparing nonpartitioned, proportional and separate models for combined molecular phylogenetic analyses of multilocus sequence data. Molecular Ecology Resources, 11 914-921. https://doi.org/10.1111/j.1755-0998.2011.03021.x

Tubaki, K. (1973). Aquatic sediment as a habitat of Emericellopsis, with a description of an undescribed species of Cephalosporium. Mycologia, 65, 938-941. https://doi.org/10.1080/00275514.1973.12019506

Udagawa, S., \& Furuya, K. (1988). Emericellopsis sphaerospora and Kernia peruviana, two new soil-borne cleistothecial ascomycetes. Mycotaxon, 33, 291-301.

van Beyma thoe Kingma, F. H. (1940) Beschreibung einiger neuer pilzarten aus dem centraalbureau voor schimmelcultures, Baarn (Nederland), VI. Mitteilung. Antonie van Leeuwenhoek, 6, 263-290. https://doi.org/10.1007/BF02272784

Vilgalys, R., \& Hester, M. (1990). Rapid genetic identification and mapping of enzymatically amplified ribosomal DNA from several Cryptococcus species. Journal of Bacteriology, 172, 4238-4246. https://doi.org/10.1128/jb.172.8.42384246.1990

White, T. J., Bruns, T., Lee, S., \& Taylor, J. W. (1990). Amplification and direct sequencing of fungal ribosomal RNA genes for phylogenetics. In: M. A. Innis, D. H. Gelfand, J. J. Sninsky, \& J. W. Thomas (Eds.), PCR protocols: a guide to methods and applications (pp. 315-322). San Diego, CA: Academic Press.

Zuccaro, A, Summerbell, R. C., Gams, W., Schroers, H. J., \& Mitchell, J. I. (2004). A new Acremonium species associated with Fucus spp., and its affinity with a phylogenetically distinct marine Emericellopsis clade. Studies in Mycology, 50, 283-297. 